\title{
Expressão do fenótipo em populações segregantes de aveia conduzidas em diferentes ambientes
}

\author{
Phenotype expression in oat segregant populations under differents environments
}

\author{
Volmir Sergio Marchioro ${ }^{1}{\text { Fernando Irajá Félix de Carvalho }{ }^{2} \text { Antônio Costa de Oliveira }}^{2}$ \\ Claudir Lorencetti ${ }^{3}$ Giovani Benin ${ }^{3}$ José Antônio Gonzales da Silva ${ }^{3}$ Adeliano Cargnin $^{4}$ \\ Daniel Simioni ${ }^{4}$
}

\section{RESUMO}

A seleção com base no fenótipo pode ser influenciada por fatores de ambiente, sendo necessário que o melhorista utilize métodos de seleção que separem efeitos genéticos dos de ambiente. O objetivo deste trabalho foi avaliar os componentes do rendimento de populações segregantes de aveia em diferentes métodos de semeadura. Oito populações foram conduzidas em três métodos de semeadura: planta espaçada, cova e linha cheia, em delineamento de blocos casualizados, com duas repetições. Foram selecionadas as panículas com peso superior à média mais um desvio padrão e, a partir destas, obtidos os caracteres peso de grãos e número de grãos por panícula. Os resultados revelaram uma interação significativa das populações com o ambiente. A herdabilidade foi alta, exceto para o caráter número de grãos/panícula na de semeadura em linha cheia. $O$ peso de panícula pode ser um caráter de alta eficiência na seleção de genótipos superiores para o incremento no rendimento de grãos.

Palavras-chave: Avena sativa L., métodos de semeadura, herdabilidade.

\section{ABSTRACT}

Selection on the phenotype basis can be affected by environmental factors; forcing the plant-breeder to isolate genetic and environmental factors. The objective of this work was to evaluate the yield components of oat segregant populations subjected to different methods. Eight populations were planted in random block design with two replicates, according to three different models: spaced plant, full line and hill. Panicles with weight higher than mean plus one standard deviation were selected and measured for grain weight and grain number per panicle. Results showed a significant interaction between populations and environmental factors. Heritability was high, excepted for grain number/panicle on the full line models. Panicle weight can be an efficient trait to select genotypes in order to order increase grain yield.

Key words: Avena sativa L., sowing methods, heritability.

\section{INTRODUÇÃO}

O efeito do ambiente é um fator limitante ao melhorista, impedindo muitas vezes que a seleção realizada com base no fenótipo da planta constitua um genótipo desejado (ALLARD, 1960). A existência de respostas diferenciadas de genótipos aos efeitos de ambiente tem sido freqüentemente constatada nas várias espécies de plantas cultivadas. Esta interação, além de influenciar os ganhos genéticos, dificulta a recomendação de genótipos, para ambientes distintos. Deste modo, a identificação de qual o melhor ambiente para o incremento na eficiência de um programa de melhoramento, principalmente em função do rendimento de grãos, tem sido outro obstáculo dos melhoristas (HILL et al. 1998), principalmente pelos custos associados a este processo (ALLEN et al. 1977)

${ }^{1}$ Engenheiro Agrônomo, estudante do Curso de Doutorado em Agronomia (Fitomelhoramento) da Universidade Federal de Pelotas (UFPel), Pelotas-RS. Bolsista da Capes. E-mail: volmirsm@ufpel.tche.br - vmarchioro@bol.com.br.

${ }^{2}$ Engenheiro Agrônomo, PhD, Professor do Departamento de Fitotecnia, Faculdade de Agronomia Eliseu Maciel, UFPel, Campus Universitário, CP 354, 96001-970, Pelotas-RS. E mail: caravalho@ufpel.tche.br. Autor para correspondência.

${ }^{3}$ Engenheiro Agrônomo, estudante do Curso de Pós-graduação em Agronomia (Fitomelhoramento) da UFPel.

${ }^{4}$ Estudante do Curso de Agronomia da UFPel - Bolsista do CNPq. 
e a necessidade de identificar genótipos com ajuste a todas as áreas de cultivo da aveia no sul do Brasil, (adaptabilidade).

Segundo CRUZ et al. (1983), a seleção sobre caracteres quantitativos em ambientes instáveis merece estudos mais aprofundados, principalmente no desenvolvimento de mecanismos que possibilitem a identificação de uma maior correlação entre o genótipo e o fenótipo de indivíduos superiores. Para ROSIELLE \& HAMBLING (1981), a variação nas condições de ambiente, tanto em relação aos locais de cultivo como as alterações de ano para ano impedem a identificação de um ambiente que maximize o ganho genético para as constituições genéticas.

Trabalhos de pesquisa têm demonstrado a necessidade de criar novos critérios como estratégia de modificação de técnicas convencionalmente utilizadas em cereais de estação fria (SANTOS \& CARVALHO, 1977; CRUZ et al. 1983), e estabelecer critérios de reconhecimento, com maior exatidão, das diferenças genéticas e dos efeitos de ambiente.

A estimativa da herdabilidade, segundo FREY (1964) e ATLIN \& FREY (1964) tem sido um bom parâmetro para a identificação do melhor ambiente de seleção para distintos caracteres; entretanto, para ALLEN et al. (1977) e FALCONER \& MACKAY (1996), além da herdabilidade, a correlação genética entre a população no ambiente teste e o ambiente de produção poderá otimizar o ganho de seleção. A seleção de genótipos superiores, segundo FALCONER \& MACKAY (1996), pode ser feita através de seus componentes do rendimento, visto que apresentam uma correlação direta com o rendimento, embora revelem coeficientes de herdabilidade reduzidos.

Poucos trabalhos têm sido desenvolvidos em relação ao potencial de seleção indireta para o rendimento de grãos de aveia através do peso de panícula e seus componentes. CHAPKO \& BRINKMAN (1991) encontraram um coeficiente de correlação de até $70 \%$ entre o peso de panícula e o rendimento de grãos e reforçam dados de SAMPSON (1971), que revelaram a potencialidade deste tipo de seleção nas primeiras gerações, em ambientes com pequeno espaçamento entre plantas (competição mais acentuada entre indivíduos da população).

De acordo com SAMPSON (1971), o peso da panícula em aveia tem grande potencial para a seleção indireta de plantas superiores para rendimento de grãos em gerações segregantes; contudo, para que o sucesso seja alcançado a seleção deverá ser realizada a campo e sobre plantas com espaçamento reduzido. Nestas condições, outros autores também obtiveram resultados significativos para incremento no rendimento de grãos em gerações altamente segregantes, através da seleção indireta de componentes do rendimento, tais como MCNEAL et al. (1978), em trigo, e GRAVOIS \& MCNEW (1993), em arroz.

CAIERÃO (2000) relatou que a alta relação grão/palha da panícula de aveia e a estabilidade frente à modificação dos ambientes reforçam a possibilidade de sucesso da utilização do peso de panícula como critério de seleção indireta para rendimento de grãos, devido à alta correlação entre estes caracteres.

Conforme CHANDHANAMUTTA \& FREY (1973), 80\% do incremento no rendimento de grãos em aveia pode ser atribuído ao aumento no número de grãos por panícula, e apenas $20 \%$ ao aumento no peso de grãos. Devido a esta contribuição dos componentes do rendimento, e à existência de uma correlação positiva entre o peso de panícula e o rendimento de grãos em aveia, a aplicação da seleção indireta parece ser uma técnica importante na seleção de constituições genéticas superiores para o incremento no rendimento de grãos.

Neste sentido, o presente trabalho teve como objetivo avaliar o comportamento dos componentes do rendimento de populações segregantes de aveia em diferentes métodos de semeadura, como forma de reforçar a possibilidade de seleção indireta para o rendimento de grãos.

\section{MATERIAL E MÉTODOS}

O experimento foi instalado no campo experimental do Setor de Fitomelhoramento da Faculdade de Agronomia Eliseu Maciel - UFPel, no município de Capão do Leão, no ano agrícola de 2000. As populações segregantes na geração $\mathrm{F}$ de aveia, inseridas no experimento foram: UPF 7 x ƯFRGS 14, UFRGS 14 x OR 2, UPF 7 x OR 2, UFRGS 18x UPF 16, UFRGS 18 x OR 2, UPF 16 x OR 2, UPF 17 x UFRGS 18 e UFRGS 18 x UPF 14.

Estas populações foram conduzidas em três diferentes métodos de semeadura: em planta espaçada, em linha cheia e em cova, este último descrito como método "Hill", por FREY (1965), que consiste na semeadura em covas, com um número determinado de sementes por cova. O delineamento utilizado no experimento foi o de blocos completos casualizados, com duas repetições. No método de semeadura em cova, as parcelas foram compostas de dez covas com 10 sementes por cova, espaçadas em $45 \mathrm{~cm}$ entre covas. No método de semeadura em planta espaçada as parcelas foram compostas de dez linhas de $2 \mathrm{~m}$ de comprimento espaçadas em $20 \mathrm{~cm}$ entre linhas e entre 
plantas e, no método de semeadura em linha cheia, as parcelas foram compostas de duas linhas de $2 \mathrm{~m}$ de comprimento com 60 sementes aptas por metro linear.

Após a maturação, foram colhidas todas as panículas, nos três métodos de semeadura das populações segregantes. Depois de obtido o peso de panícula (PP), as panículas com peso superior a média mais um desvio padrão, dentro de cada cova, dentro de cada linha de planta espaçada e dentro de cada linha cheia foram selecionadas, para todos os oito cruzamentos nas duas repetições. As panículas com peso inferior a média mais um desvio padrão foram descartadas, e as selecionadas foram trilhadas individualmente para se obter as variáveis, peso de grãos/panícula (PGP) e número de grãos/panícula (NGP).

A partir das médias obtidas dentro da repetição, para as oito populações segregantes, foi efetuada a análise de variância conjunta, utilizandose o modelo estatístico: $Y_{i j k}=\mu+(b / m)_{j k}+g_{i}+m_{j}+$ $g m_{i j}+\varepsilon_{i j k}$, onde, $Y_{i j k}$ : observação no $k$-ésimo bloco, avaliado no $i$-ésimo genótipo e $j$-ésimo método; $\mu$ : média geral do experimento; $(\mathrm{b} / \mathrm{m})_{j k}$ : efeito do bloco $k$ dentro do método $j ; g_{i}$ : efeito do genótipo $i ; m_{j}$ : efeito do método $j ; g m_{i j}$ : efeito da interação entre o genótipo $i$ e o método $j ; \varepsilon_{i j k}$ : erro aleatório associado à observação $i j k$. Também foi efetuada a análise individual, utilizando o modelo estatístico: $Y_{i j}=\mu+$ $g_{i}+b_{j}+\varepsilon_{i j}$, onde, $Y_{i j}$ : observação no $i$-ésimo genótipo na $j$-ésimo bloco; $\mu$ : média geral do experimento; $g_{i}$ : efeito do genótipo $i ; b_{j}$ : efeito do bloco $j ; \varepsilon$ : erro aleatório associado à observação $i j$ (CRUZ, 20̈01).

A análise de comparação de médias foi realizada utilizando o teste descrito por SCOTT \& KNOTT (1974); o emprego deste teste de comparação de médias evidencia a hipótese de alta utilidade, pois possibilita a definição dos subconjuntos de genótipos que diferem significativamente entre si. Para estimar os parâmetros genéticos dentro e entre os diferentes métodos de semeadura das populações segregantes, foram analisados os componentes da variação em cada ambiente individual, pela contribuição do quadrado médio esperado (QME), conforme ilustrado na tabela 1, onde variância: $\sigma^{2}=\mathrm{QM}, \sigma^{2}{ }_{\mathrm{G}}$ $=\mathrm{QM}_{\mathrm{G}}-\mathrm{QM}_{\mathrm{E}} / \mathrm{r}, \sigma_{\mathrm{P}}^{2}=\sigma^{2}{ }_{\mathrm{G}}-\sigma_{\mathrm{E}}^{2} \mathrm{e} \mathrm{h}^{2}=\mathrm{\sigma}_{\mathrm{G}}{ }_{\mathrm{G}} / \sigma_{\mathrm{P}}^{2}{ }^{\mathrm{E}}$ Esta técnica permite avaliar a existência de variabilidade genética entre as médias dos genótipos envolvidos em cada ambiente, o que fornece informações sobre a magnitude dos parâmetros genéticos para cada ambiente separadamente, e as discrepâncias entre as variâncias residuais, (CARVALHO et al. 2001).

\section{RESULTADOS E DISCUSSÃO}

As populações avaliadas no experimento interagiram significativamente com o ambiente para as três variáveis consideradas (Tabela 2). Estes resultados mostram a dependência das condições de ambiente para a expressão do fenótipo. Segundo FALCONER \& MACKAY (1996), esta oscilação na expressão do fenótipo pode ser justificada pelo fato de os caracteres estudados serem de natureza quantitativa, ou seja, determinados por vários genes sendo cada gene com pouco efeito no caráter e altamente influenciado pelo ambiente. Também é possível constatar (Tabela 2), que para as três variáveis, os fatores população e método de semeadura foram significativos. Isto mostra que a maximização do ganho genético, no momento da seleção, pode ser influenciada pelo método de semeadura.

As médias para o caráter peso de panícula (PP) mostraram diferenças significativas entre si (Tabela 3), com três classes distintas ("a", "b" e "c"), na semeadura em cova; quatro classes ("a", "b", "c" e "d") na semeadura em planta espaçada e quatro classes ("a", "b", "c", "d" e "e") na semeadura em linha cheia.

Tabela 1 - Componentes da variação da análise conjunta e individual para os três métodos de semeadura das populações segregantes

\begin{tabular}{|c|c|c|c|c|c|c|}
\hline \multirow[t]{2}{*}{ Fontes de variação } & \multicolumn{3}{|c|}{ Análise conjunta } & \multicolumn{3}{|c|}{ Análise individual } \\
\hline & GL & QM & QME & GL & QM & QME \\
\hline Repetição (R) & $\mathrm{m}(\mathrm{r}-1)$ & $\mathrm{QM}_{\mathrm{R}}$ & $\sigma_{E}^{2}+g \sigma_{R}^{2}$ & $\mathrm{r}-1$ & $\mathrm{QM}_{\mathrm{R}}$ & $\sigma_{E}^{2}+g \sigma_{R}^{2}$ \\
\hline População (G) & g-1 & $\mathrm{QM}_{\mathrm{G}}$ & $\begin{array}{l}\sigma_{\mathrm{E}}^{2}+\mathrm{r}_{\mathrm{GM}}^{2}+\mathrm{g} \sigma_{\mathrm{R}}^{2} \\
+\mathrm{gr} \sigma_{\mathrm{M}}^{2}\end{array}$ & $\mathrm{~g}-1$ & $\mathrm{QM}_{\mathrm{G}}$ & $\sigma_{E}^{2}+r \sigma_{G}^{2}$ \\
\hline Método (M) & $\mathrm{m}-1$ & $\mathrm{QM}_{\mathrm{M}}$ & $\sigma_{\mathrm{E}}^{2}+r \sigma_{\mathrm{GA}}^{2}+m r \sigma_{\mathrm{G}}^{2}$ & & & \\
\hline $\mathrm{G} \times \mathrm{M}$ & $(\mathrm{g}-1)(\mathrm{m}-1)$ & $\mathrm{QM}_{\mathrm{GE}}$ & $\sigma_{E}^{2}+r \sigma_{G M}^{2}$ & & & \\
\hline Resíduo & $(\mathrm{r}-1)(\mathrm{g}-1) \mathrm{m}$ & $\mathrm{QM}_{\mathrm{E}}$ & $\sigma_{E}^{2}$ & $(\mathrm{~g}-1)(\mathrm{r}-1)$ & $\mathrm{QM}_{\mathrm{E}}$ & $\sigma_{\mathrm{E}}^{2}$ \\
\hline Total & grm -1 & & & & & \\
\hline
\end{tabular}


Tabela 2 - Análise de variância para os caracteres peso de panícula (PP), peso de grãos/panícula (PGP) e número de grãos/panícula (NGP), para as oito populações segregantes, nos três métodos de semeadura.

\begin{tabular}{llccr}
\hline & & \multicolumn{3}{c}{ Quadrado médio } \\
\cline { 3 - 5 } Fontes de variação & GL & PP & PGP & NGP \\
\hline População (G) & 7 & $1,352^{*}$ & $1,238^{*}$ & $737,28^{*}$ \\
Método (M) & 2 & $9,271^{*}$ & $6,051^{*}$ & $6867,00^{*}$ \\
G x M & 14 & $0,059^{*}$ & $0,062^{*}$ & $164,07 *$ \\
\hline
\end{tabular}

*significativo em $5 \%$ de probabilidade de erro.

Por outro lado os caracteres peso de grãos/panícula (PGP) e número de grãos/panícula (NGP) apresentaram respectivamente, uma única classe ("a") e duas classes ("a" e "b") em todos os métodos de semeadura das populações. Portanto, há evidências de que o peso de panícula (PP) parece ser o caráter mais eficiente como estratégia de identificação de constituições genéticas distintas em qualquer um dos ambientes testados. Além disso, é um caráter de fácil aferição, bastando apenas colher e pesar as panículas, sem necessidade de trilhar as mesmas. Por outro lado, para se obter os caracteres peso de grãos/panícula (PGP) e número de grãos/ panícula (NGP), é necessário efetuar a trilha das panículas, tornando mais árduo o trabalho dos melhoristas, que normalmente trabalham com um grande número de plantas durante o processo de seleção.

Através da análise de variância individual, em cada ambiente, foi possível estimar os parâmetros genéticos dos caracteres avaliados (Tabela 4). A contribuição genética presente na manifestação dos caracteres foi altamente herdável, exceto para o caráter número de grãos/panícula (NGP) no método de semeadura em linha cheia, concordando com os dados obtidos por FALCONER \& MACKAY (1996), que encontrou estimativa diferenciada de herdabilidade em condições de ambientes particulares. É importante ressaltar que a herdabilidade foi calculada em caracteres obtidos a partir de panículas selecionadas, o que talvez tenha contribuído para os altos valores obtidos para a estimativa da herdabilidade dos caracteres estudados. A forte participação da competição entre plantas, neste método, provavelmente tenha contribuído de forma positiva e negativa em torno da média do fenótipo, tornando a relação variâncias genética e fenotípica muito estreita.

A contribuição genética foi mais importante que os efeitos de ambiente (Tabela 4), concordando com dados de MURPHY \& FREY (1962), que encontraram também, altos valores de herdabilidade para peso de grãos e outras variáveis quantitativas em aveia. Os resultados revelaram uma tendência a ganhos de seleção mais promissores para o caráter peso de panícula (PP) na semeadura em planta espaçada, comparado com os métodos de semeadura em cova e linha cheia. Resultados similares foram obtidos por ROY \& MURTY (1970), que relacionam a maior herdabilidade com o melhor ambiente de seleção.

Esse fato é justificado pela relação grão/ palha (Tabela 3), que foi estável frente à modificação dos ambientes (85,8 na semeadura em cova, 83,2 na

Tabela 3 - Médias dos caracteres peso de panícula (PP), peso de grãos/panícula (PMG) e número de grãos/panícula (NGP), coeficiente de variação (C.V.) e a relação grão/palha, nos três métodos de semeadura.

\begin{tabular}{|c|c|c|c|c|c|c|c|c|c|}
\hline \multirow{3}{*}{ Genótipos } & \multicolumn{9}{|c|}{ Método de semeadura } \\
\hline & \multicolumn{3}{|c|}{ Em cova } & \multicolumn{3}{|c|}{ Em planta espaçada } & \multicolumn{3}{|c|}{ Em linha cheia } \\
\hline & $\mathrm{PP}$ & PGP & NGP & $\mathrm{PP}$ & PGP & NGP & PP & PGP & NGP \\
\hline UPF 7 x UFRGS 14 & $5,09 \mathrm{a}$ & $4,42 \mathrm{a}$ & $113,0 \mathrm{~b}$ & $5,96 \mathrm{a}$ & $5,20 \mathrm{a}$ & $119,5 \mathrm{~b}$ & $4,15 \mathrm{a}$ & $3,39 \mathrm{a}$ & $80,5 \mathrm{~b}$ \\
\hline OR 2 x UFRGS 14 & $3,63 \mathrm{c}$ & $3,18 \mathrm{a}$ & $100,5 \mathrm{~b}$ & $4,56 \mathrm{~d}$ & $3,81 \mathrm{a}$ & $120,0 \mathrm{~b}$ & $3,18 \mathrm{~d}$ & $2,85 \mathrm{a}$ & $79,0 \mathrm{~b}$ \\
\hline OR 2 x UPF 7 & $3,58 \mathrm{c}$ & $2,93 \mathrm{a}$ & $136,0 \mathrm{a}$ & $4,58 \mathrm{~d}$ & $3,77 \mathrm{a}$ & $133,5 \mathrm{~b}$ & $2,90 \mathrm{e}$ & $2,37 \mathrm{a}$ & $93,0 \mathrm{~b}$ \\
\hline UPF 16 x UFRGS 18 & $4,34 \mathrm{~b}$ & $3,53 \mathrm{a}$ & $135,5 \mathrm{a}$ & $5,32 \mathrm{~b}$ & $4,40 \mathrm{a}$ & $149,5 \mathrm{a}$ & $3,47 \mathrm{c}$ & $3,02 \mathrm{a}$ & $95,0 \mathrm{a}$ \\
\hline OR 2 x UFRGS 18 & $3,51 \mathrm{c}$ & $2,95 \mathrm{a}$ & $103,0 \mathrm{~b}$ & $4,42 \mathrm{~d}$ & $3,51 \mathrm{a}$ & $125,5 \mathrm{~b}$ & $3,14 \mathrm{~d}$ & $2,47 \mathrm{a}$ & $86,5 \mathrm{~b}$ \\
\hline OR 2 x UPF 16 & $4,25 \mathrm{~b}$ & $3,72 \mathrm{a}$ & $121,5 \mathrm{a}$ & $5,04 \mathrm{c}$ & $4,18 \mathrm{a}$ & $154,0 \mathrm{a}$ & $3,39 \mathrm{c}$ & $2,87 \mathrm{a}$ & $92,0 \mathrm{~b}$ \\
\hline UPF 17 x UFRGS 18 & $4,19 \mathrm{~b}$ & $3,61 \mathrm{a}$ & $92,0 \mathrm{~b}$ & $5,01 \mathrm{c}$ & $4,32 \mathrm{a}$ & $114,0 \mathrm{~b}$ & $3,86 \mathrm{~b}$ & $3,40 \mathrm{a}$ & $87,0 \mathrm{~b}$ \\
\hline UPF 14 x UFRGS 18 & $3,52 \mathrm{c}$ & $3,18 \mathrm{a}$ & $102,5 \mathrm{~b}$ & $4,67 \mathrm{~d}$ & $3,71 \mathrm{a}$ & $126,0 \mathrm{~b}$ & $3,39 \mathrm{c}$ & $2,71 \mathrm{a}$ & $99,0 \mathrm{a}$ \\
\hline Médias & 4,01 & 3,44 & 113,0 & 4,94 & 4,11 & 130,3 & 3,43 & 2,88 & 89,0 \\
\hline $\mathrm{CV}(\%)$ & 5,26 & 5,75 & 8,12 & 1,77 & 2,40 & 4,52 & 2,34 & 5,22 & 9,89 \\
\hline Rel. grão/palha (\%) & & 85,8 & & & 83,2 & & & 82,5 & \\
\hline
\end{tabular}


Tabela 4 - Estimativas dos parâmetros genéticos para os caracteres peso de panícula (PP), peso de grãos/panícula (PGP) e número de grãos/panícula (NGP) para as oito populações segregantes, nos três métodos semeadura.

\begin{tabular}{|c|c|c|c|c|c|}
\hline Métodos de semeadura & Variáveis & $\sigma_{G}^{2}$ & $\sigma_{E}^{2}$ & $\sigma_{\mathrm{P}}^{2}$ & $\mathrm{~h}^{2}$ \\
\hline \multirow[t]{3}{*}{ Em cova } & PP & 0,290 & 0,045 & 0,335 & 0,86 \\
\hline & PGP & 0,225 & 0,039 & 0,264 & 0,85 \\
\hline & NGP & 231,427 & 84,286 & 315,713 & 0,73 \\
\hline \multirow[t]{3}{*}{ Em planta espaçada } & PP & 0,256 & 0,008 & 0,264 & 0,97 \\
\hline & PGP & 0,287 & 0,010 & 0,297 & 0,96 \\
\hline & NGP & 192,714 & 34,714 & 227,429 & 0,84 \\
\hline \multirow[t]{3}{*}{ Em linha cheia } & PP & 0,159 & 0,006 & 0,165 & 0,96 \\
\hline & PGP & 0,133 & 0,023 & 0,156 & 0,85 \\
\hline & NGP & 38,304 & 44,071 & 82,375 & 0,46 \\
\hline
\end{tabular}

semeadura em planta espaçada e 82,5 na semeadura em linha cheia), ou seja, panículas mais pesadas em um determinado ambiente podem ser empregadas como critério de seleção indireta para o rendimento de grãos.

\section{CONCLUSÕES}

Os efeitos da competitividade entre indivíduos de uma população alteram a herdabilidade e os componentes da variância de caracteres quantitativos, justificando a escolha de ambiente, em que o efeito da seleção natural é menor. $\mathrm{O}$ peso de panícula pode ser um caráter eficiente na seleção indireta de genótipos superiores para o incremento no rendimento de grãos em aveia.

\section{REFERÊNCIAS BIBLIOGRÁFICAS}

ALLARD, R.W. Principles of plant breeding. New York: John Willey \& Sons, 1960. 485p.

ALLEN, F.L.; COMSTOCK, R.E.; RASMUSSON, D.C. Optimal environments for yield testing. Crop Science, Madison, v.17, p.747-751, 1977.

ATLIN, G.N.; FREY, K.J. Selecting oat lines for yield in lowproductivity environments. Crop Science, Madison, v.30, p.556-561, 1964.

CAIERÃO, E. Peso de panícula como critério de seleção indireta para rendimento de grãos em aveia. 2000 . 180f. Dissertação (Mestrado em Fitomelhoramento) - Curso de Pós-graduação em Agronomia, Universidade Federal de Pelotas.

CARVALHO, F.I.F. et al. Estimativas e implicações da herdabilidade como estratégia de seleção. Pelotas : UFPel, 2001. 99p.

CHANDHANAMUTTA, P.; FREY, K.J. Indirect mass selection for grain yield in oat populations. Crop Science, Madison, v.13, p.470-473, 1973.
CHAPKO, L.B.; BRINKMAN, M.A. Interrelationships between panicle weight, grain yield on grain yield components in oat. Crop Science, Madison, v.31, p.878-882, 1991.

CRUZ, C.D. Programa genes: aplicativo computacional em genética e estatística. Viçosa : UFV, 2001. 648p.

CRUZ, P.J.; CARVALHO, F.I.F.; FEDERIZZI, L.C. Efeitos de populações e métodos de seleção aplicados em gerações segregantes de trigo. Pesquisa Agropecuária Brasileira, Brasília, v.18, n.5, p.533-541, 1983.

FALCONER, D.S.; MACKAY, T.F.C. Introduction to quantitative genetics. 4.ed. Edinburgh : Longman Group Limited, 1996. 464p.

FREY, K.J. Adaptation reaction of oat strains selected under stress and nonstress environmental conditions. Crop Science, Madison, v.4, p.55-58, 1964.

FREY, K.J. The utility of hill plots in oat research. Euphytica, Wageningen, v.14, p.196-208, 1965.

GRAVOIS, K.A.; MCNEW, R.W. Genetic relationships among and selection for rice yield and yield components. Crop Science, Madison, v.33, p.249-252, 1993.

HILL, J.; BECKER, H.C.; TIGERSTEDT, P.M.A. Quantitative and ecological aspects of plant breeding. London : Chapman \& Hall, 1998. 288p.

MCNEAL, F.H. et al. Selection for yield and yield components in wheat. Crop Science, Madison, v.18, p.795-799, 1978.

MURPHY, C.F.; FREY, K.J. Inheritance and heritability of seed weight and its components in oats. Crop Science, Madison, v.2, p.509-512, 1962.

ROSIELlE, A.A.; HAMBLING, J. Theoretical aspects of selection for yield in stress and nonstress environments. Crop Science, Madison, v.21, p.293-946, 1981.

ROY, N.N.; MURTY, O.R. A selection procedure in wheat for stress environment. Euphytica, Madison, v.19, p.509-521, 1970.

SAMPSON, D.R. Additive and nonadditive genetic variances and genotype correlations for yield and other traits in oats. Canadian Journal Genetics Cytology, Ottawa, v.13, p.864-872, 1971 .

Ciência Rural, v. 33, n. 4, jul-ago, 2003. 
SANTOS, F.G.; CARVALHO, F.I.F. Estimativa da seleção para caracteres de importância agronômica em gerações segregantes de trigo (Triticum aestivum L.). Agronomia Sulriograndense, Porto Alegre, v.13, n.2, p.219-236, 1977.
SCOTT, A.J.; KNOTT, M.A. Cluster analysis methods for grouping means in the analysis of variance. Biometrics, Washington, v.30, p.507512,1974 .

Ciência Rural, v. 33, n. 4, jul-ago, 2003. 